\title{
OPEN Variability in waxy $(W x)$ allele, in-vitro starch digestibility, glycemic response and textural behaviour of popular Northern Himalayan rice varieties
}

\begin{abstract}
Bazila Naseer ${ }^{1}$, H. R. Naik² ${ }^{2}$ Syed Zameer Hussain ${ }^{1 凶}$, Asif Bashir Shikari² \& Nowsheen Noor ${ }^{2}$
Eight commonly cultivated and consumed rice varieties of Northern Himalayan regions and a popular high amylose rice variety were characterized at $W x$ locus and evaluated for resistant starch (RS), in-vitro starch digestibility, predicted glycemic index (pGI), glycemic load (GL) and textural parameters. Cytosine and thymine repeats (CT)n at waxy locus (WX) showed high association with apparent amylose content (AAC). Both pGI and GL varied substantially within the selected varieties. The pGI was relatively lower in high and intermediate amylose Indica varieties compared to low amylose Japonica ones. However, Koshikari despite being a low amylose variety showed relatively lower pGI and GL, due to its higher RS, dietary fiber, protein and fat content. It was thus presumed that in addition to AAC, RS and other grain components also affect the glycemic response. Inherent resistance to enzymatic hydrolysis was also found to be higher in firm textured and less sticky rice varieties. The genotypes-Lalat, Basmati-1509 and Koshikari, in view of their low to moderate pGI and relatively higher RS content, can be explored in future breeding programmes to develop rice varieties whose consumption will help to prevent hyper/hypo glycemic responses in Northern Himalayan regions, where daily staple diet is rice.
\end{abstract}

The prevalence of type II diabetes is rapidly increasing in all the parts of the world with most severe implications on the low- and middle-income communities ${ }^{1,2}$. Globally, 463 million people are affected by diabetes, out of which 77 million are reported to be from India ${ }^{3}$. It is expected that by 2030, 578 million adults will be living with diabetes and its management will be one of the biggest health challenges in future.

Rice (Oryza Sativa L.) is the second most important cereal crop grown in the world and is the staple food to more than $60 \%$ of the world population. It holds a significant position in human nutrition. Total global consumption of rice is more than 493.12 million metric tons annually ${ }^{4}$. India is the second largest producer as well as consumer of rice in the world ${ }^{5}$. Rice is a good source of macronutrients especially carbohydrates. However, larger intake of white rice is considered as one of the major reasons for prevalence of type II diabetes in Asian population. Several cohort studies have reported that consumption of more than $300 \mathrm{~g} /$ day of white rice increases the risk of type II diabetes by $78 \%{ }^{6}$. The association of glycemic index (GI) with increased risk of metabolic syndrome and diabetes is well documented in many previous studies ${ }^{7,8}$. The regular consumption of white rice impairs the glucose metabolism and insulin resistance due to its higher $\mathrm{GI}^{7}$.

However, physico-chemical, molecular and genetic make-up determines the digestibility and glycemic response of rice. GI of high amylose rice varieties is usually lower than the waxy ones. ${ }^{9}$. Amylose is considered as one of the predominant traits which governs the cooking quality of rice. Amylose content of rice is regulated by waxy $\left(W_{x}\right)$ gene that codes for Granule Bound Starch Synthase (GBSS) protein. Simple sequence repeat (SSR) marker RM190 linked to $W x$ phenotype has been reported to explain around 60\% of variance for amylose content in rice ${ }^{10}$. The RM190 is based on dinucleotide repeat CT that varies from $(\mathrm{CT})_{8}$ to $(\mathrm{CT})_{20}$ and the marker is located in $5^{\prime}$ Untranslated Region (UTR) of Waxy exon $1^{11}$. The corresponding length of repeats within SSR fragments are associated with the specific amylose class. Fitzgerald et al. ${ }^{12}$ studied the association between amylose

${ }^{1}$ Division of Food Science and Technology, Sher-e-Kashmir University of Agricultural Sciences and Technology of Kashmir, Shalimar 190025, India. ${ }^{2}$ Department of Food Technology, Islamic University of Science and Technology, Awantipora 192122, India. ${ }^{\square}$ email: zameerskuastj@rediffmail.com 
content, waxy allele and GI in improved and traditional rice varieties of Asia. They observed strong correlations between amylose content, waxy locus and GI across all the samples which indicated that amylose is the major grain constituent that affects the GI. However, resistant starch (RS) which act as a non-glycemic starch fraction in rice also affect its digestibility. Typically, type-5 resistant starch is formed in rice due to interaction of amylose and lipids. Such complexes are composed of hydrophobic polyglucan chains and are responsible for lowering of GI due to their resistance to enzymatic hydrolysis ${ }^{13}$. Amylose-lipid complexes organize into a partially ordered structure typically known as V-type crystalline lattice ${ }^{14}$. Both, amylose and RS are inversely related to $\mathrm{GI}^{15}$. Therefore, there is a need to identify specific rice varieties having high amylose and relatively high RS content in different rice consuming regions.

Although, rice is relatively known to deliver a higher glycemic response but consumption of rice is linked to cultural preference and satiety effects among Asian population. Therefore, dietary management of type II diabetes through a staple food like rice holds a viable scope to curb its future escalation. Thus, there is a scope to screen the commonly consumed rice varieties of Northern Highland Himalayan regions for $W x$ allele characterization, in-vitro starch digestibility and glycemic index. To the best of our knowledge, rice varieties grown in Northern Highland Himalayan regions have not been tested so far for $W x$ allele characterization, in-vitro starch digestibility and glycemic index. Thus, the present study was conducted with an aim to characterize eight rice varieties commonly cultivated and consumed in Northern Highland Himalayan regions, at waxy locus (Wx) using RM190 and to study the association of amylose content with inherent allelic variation, in-vitro starch digestibility, predicted glycemic index, glycemic load and textural parameters in selected rice varieties.

\section{Material and methods}

Raw materials. Five Indica (SR-2, Basmati-1509, China-1007, Chenab and Jhelum) and three Japonica (Koshikari, SKUA-402 and K-332) paddy varieties commonly grown in Northern highland Himalayan regions were procured from the Mountain Research Centre for Field Crops, Khudwani, Sher-e-Kashmir University of Agricultural Sciences and Technology, Kashmir, (SKUAST-K), India ${ }^{16}$. While as Lalat, a high amylose rice variety was procured from Research and Seed Processing Centre, Odisha University of Agriculture and Technology, Bhubaneswar, India. The material was procured from the registered seed centers, in compliance with the institutional guidelines. All the paddy varieties were milled in a modern rice mill (ASR RM 209). Milling percentage recorded for different varieties was $70 \pm 5 \%$. Polished head rice grains obtained from each variety were dried to a moisture content of $11-12 \pm 0.5 \%$ in a cabinet drier (LSI-EC-STB), Lab Solutions, India at a temperature of $40 \pm 5{ }^{\circ} \mathrm{C}^{17}$. A portion of polished head rice grains were ground in a laboratory mill (Pertin, USA) to obtain rice flour. Both dried polished head rice gains and rice flour were stored in separate air tight containers under ambient conditions for further analysis.

Determination of apparent amylose content. Standard protocol as per Megazyme assay kit (K-AMYL 06/18) was followed for determination of apparent amylose content (AAC). Rice flour (20 mg) was mixed with $1 \mathrm{~mL}$ dimethyl sulphoxide (DMSO) in a falcon tube and stirred on a vortex shaker. The tube was placed in a boiling water bath for $1 \mathrm{~min}$ to solubilize the sample. The contents were thoroughly mixed on vortex again and then heated for $15 \mathrm{~min}$ in a boiling water bath with intermittent shaking. Ethanol $(2 \mathrm{~mL}$, 95\%) was added to tubes with continuous stirring. $4 \mathrm{~mL}$ of ethanol was added to tubes and mixing was done by inverting the capped tubes. After a resting time of $15 \mathrm{~min}$, tubes were centrifuged at $4000 \mathrm{~g}$ for $5 \mathrm{~min}$. Supernatant was discarded and tubes were dried on a tissue paper. The pellets recovered were mixed with $2 \mathrm{~mL}$ of DMSO and shaken gently. The tubes were placed in a boiling water bath for $15 \mathrm{~min}$ with intermittent mixing to prevent lump formation. Concanavalin A (Con A) ( 4 mL of $30 \%$ concentrated Con A solvent) was immediately added to tubes with thorough mixing and contents were transferred to $25 \mathrm{~mL}$ volumetric flask. The volume was raised to $25 \mathrm{~mL}$ by Con A solution and solution was filtered through Whatman filter No. $1.1 \mathrm{~mL}$ of filtered extract was mixed with $0.5 \mathrm{~mL}$ of Con A solution in Eppendorf tubes. The tubes were centrifuged after $1 \mathrm{~h}$ at $14,000 \mathrm{~g}$ for $10 \mathrm{~min}$. One $\mathrm{mL}$ of supernatant was mixed with $3 \mathrm{~mL}$ of $100 \mathrm{mM}$ sodium acetate buffer $(\mathrm{pH}=4.5)$. The tubes were heated in boiling water bath for $1 \mathrm{~min}$ followed by heating at $40{ }^{\circ} \mathrm{C}$ for another $5 \mathrm{~min}$ for temperature equilibration. The samples were incubated at $40^{\circ} \mathrm{C}$ with $0.1 \mathrm{~mL}$ of amyloglucosidase $(3300 \mathrm{U} / \mathrm{mL}) / \alpha$-amylase $(500 \mathrm{U} / \mathrm{mL})$ enzyme solution for $30 \mathrm{~min}$ and centrifuged at $2000 \mathrm{~g}$ for $5 \mathrm{~min}$. Aliquots of $0.1 \mathrm{~mL}$ were taken from supernatant and $3 \mathrm{~mL}$ of GOPOD reagent was added to each tube. Incubation of tubes were done at $40{ }^{\circ} \mathrm{C}$ for $20 \mathrm{~min}$ along with reagent blank and D-glucose standard. Absorbance of samples was measured at $510 \mathrm{~nm}$ and amylose was calculated from the standard formula given in kit manual.

Marker analysis of rice genotypes at $\boldsymbol{W} \boldsymbol{x}$ locus. A set of nine rice germplasm lines were validated at $W x$ locus on chromosome 6 with the help of simple sequence repeat (SSR) marker RM190 which is known to be associated with Granule Bound Starch Synthase (GBSS) enzyme that regulates amylose content in rice and exhibits dinucleotide $(\mathrm{CT})_{\mathrm{n}}$ repeat polymorphism. The genomic DNA was extracted from young, fresh and healthy 2 weeks old seedlings following CTAB (Cetyl-Tri-Methyl Ammonium Bromide) method as described by Murray and Thompson ${ }^{18}$. Polymerase Chain Reaction (PCR) reaction mix contained $\sim 25$ ng of DNA, 10x PCR buffer (10 mMTris, pH 8.4, $50 \mathrm{mMKCl}, 1.8 \mathrm{mM} \mathrm{MgCl}_{2}$ ), 2 mM dNTPs (Thermo Fisher Scientific, Waltham, USA), 5 pmol each of forward and reverse primer and 3 U of Taq DNA polymerase (Thermo Fisher Scientific, Waltham, USA a) in a reaction volume of $10 \mu \mathrm{L}$. After an initial denaturation step of $94^{\circ} \mathrm{C}$ for $5 \mathrm{~min}$, the amplification was carried out for 35 cycles comprising $30 \mathrm{~s}$ each of $94^{\circ} \mathrm{C}, 55^{\circ} \mathrm{C}$ and $72^{\circ} \mathrm{C}$. The final extension step was performed for $10 \mathrm{~min}$ at $72{ }^{\circ} \mathrm{C}$ followed by storage at $40^{\circ} \mathrm{C}$. PCR products were resolved through Polyacrylamide Gel Electrophoresis. Non-denaturing polyacrylamide gel (12\%) was prepared by dissolving $29 \mathrm{~g}$ of acrylamide and $1 \mathrm{~g}$ of $\mathrm{N}, \mathrm{N}^{\prime}$-methylene-bis-acrylamide in $0.5 \times \mathrm{TBE}$ buffer. Afterwards $20 \%$ ammonium persulfate (APS) 
solution was also prepared. Polymerization of gel was affected by addition of $20 \mu \mathrm{L}$ of tetramethyl-ethylenediamine (TEMED) and $200 \mu \mathrm{L}$ fresh $20 \%$ APS. About $10 \mu \mathrm{L}$ of PCR product was loaded into each well of the polyacrylamide gel along with a 100 bp size DNA ladder (Thermo Fisher Scientific, Waltham, USA). And finally the gel was run at a constant voltage of $110 \mathrm{~V}$ until the dye reached a defined position, normally for $\sim 70 \mathrm{~min} .1 \mathrm{~L}$ of fresh impregnation solution was prepared by dissolving $1.5 \mathrm{~g}$ of $\mathrm{AgNO}_{3}$ in $1 \mathrm{~L}$ of distilled water followed by preparation of $1 \mathrm{~L}$ of fresh development solution by dissolving $10 \mathrm{~g}$ of $\mathrm{NaOH}$ in $900 \mathrm{~mL}$ of distilled water. After adding $1 \mathrm{~mL}$ of $37 \%$ formaldehyde, the final volume was adjusted to $1 \mathrm{~L}$. After electrophoresis, the polyacrylamide gels were stained using the above silver staining protocol, which unambiguously detected the banding pattern of SSR marker ${ }^{19}$.

Cooking of rice grains. Head rice grains $(5 \mathrm{~g})$ were placed in a beaker containing $100 \mathrm{~mL}$ of hot boiling water. Grains were cooked in a boiling water bath $\left(100 \pm 2{ }^{\circ} \mathrm{C}\right)$ for $15 \mathrm{~min}$. After $15 \mathrm{~min}$ and every minute thereafter, 1-2 grains were examined by pressing between two glass slides to check if any opaque core was left uncooked. All the varieties were cooked in a similar manner till $90 \%$ of grains became translucent and were completely cooked ${ }^{20}$. Cooking was completed in about $20 \pm 2 \mathrm{~min}$ and excess water was drained. Cooked and drained kernels were analyzed for below mentioned parameters.

Resistant starch. Resistant starch content of cooked rice was measured as per the standard AACC protocol ${ }^{21}$ using Megazyme Assay Kit (Megazyme International, Wicklow, Ireland). $100 \mathrm{mg}$ of homogenized sample was put into falcon tubes ensuring no residue remains adhered to the walls. Four $\mathrm{mL}$ of pancreatic alpha-amylase (Sigma-Aldrich, UK) (10 mg/mL in Tris-maleate buffer, pH 6.0) and $300 \mu \mathrm{L}$ of amyloglucosidase (AMG) (Megazyme, $3300 \mathrm{U} / \mathrm{mL}$ ) was added to samples and shaken vigorously followed by incubation in a shaking water bath for $16 \mathrm{~h}$ at $37^{\circ} \mathrm{C}$. Tubes were removed $16 \mathrm{~h}$ latter and absolute ethanol $(4 \mathrm{~mL})$ was added to each tube followed by vigorous stirring. Tubes were centrifuged for $10 \mathrm{~min}$ at $1500 \mathrm{~g}$ and decanted pellets were re-dissolved in $2 \mathrm{~mL}$ and $6 \mathrm{~mL}$ of ethanol (50\%) in two steps with continuous stirring and centrifugation was repeated again. Potassium hydroxide solution $(2 \mathrm{~mL}, 2 \mathrm{~mol} / \mathrm{L})$ was added to tubes and stirred for $25 \mathrm{~min}$ in an ice-bath to dissolve the pellets. $8 \mathrm{~mL}$ of sodium acetate buffer $(1.2 \mathrm{~mol} / \mathrm{L}, \mathrm{pH} 3.8)$ was added to each tube and stirring was done on a magnetic stirrer followed by addition of $0.1 \mathrm{~mL}$ of AMG solution $(3300 \mathrm{U} / \mathrm{mL})$. The contents were mixed again and incubated at $50{ }^{\circ} \mathrm{C}$ in water bath for $30 \mathrm{~min}$. Aliquot of $0.1 \mathrm{~mL}$ was taken after centrifugation at $2000 \mathrm{~g}$ for $10 \mathrm{~min} .3 \mathrm{~mL}$ of Glucose oxidase/peroxidase (GOPOD) reagent [for preparation of GOPOD reagent, glucose oxidase $(>12,000 \mathrm{U})$, peroxidase $(>650 \mathrm{U})$ and 4-aminoantipyrine $(80 \mathrm{mg})$ supplied as freeze dried powder was dissolved in $50 \mathrm{~mL}$ of GOPOD buffer (p-hydroxybenzoic acid and sodium azide $(0.09 \% \mathrm{w} / \mathrm{v})$ ] was added to aliquots in duplicate followed by incubation at $50{ }^{\circ} \mathrm{C}$ for $20 \mathrm{~min}$. Absorbance was measured at $510 \mathrm{~nm}$ (UV-Vis spectrophotometer, ThermoSpectronic, USA) against reagent blank and RS was calculated from the formula given in the instruction manual.

In-vitro starch digestibility, predicted glycemic index and glycemic load. In-vitro starch digestibility and predicted glycemic index were determined by the standard protocol given by Goñi et al. ${ }^{22}$. All the cooked rice samples (100 mg) were homogenized uniformly for 3 min using Ultra Turrax homogenizer (T25, Ika Labortechnik) to obtain a slurry. These slurry state samples were treated with $10 \mathrm{~mL}$ of $1 \mathrm{M} \mathrm{HCl}-\mathrm{KCl}$ buffer and mixed thoroughly. This was followed by addition of $0.2 \mathrm{~mL}$ pepsin solution $(1 \mathrm{~g}$ prepared in $10 \mathrm{~mL}$ of $1 \mathrm{M} \mathrm{HCl}$ $\mathrm{KCl}$ buffer, $\mathrm{pH}=1.5$ ) and incubation at $40{ }^{\circ} \mathrm{C}$ for $60 \mathrm{~min}$ in a shaking water bath. Volume was raised to $25 \mathrm{~mL}$ by adding $15 \mathrm{~mL}$ of $0.1 \mathrm{M}$ tris-maleate buffer $(\mathrm{pH}=6.9)$ followed by stirring and immediately $5 \mathrm{~mL} \alpha$-amylase solution $(10 \mathrm{mg} / \mathrm{mL}$ in $0.1 \mathrm{M}$ tris-maleate buffer, $2.6 \mathrm{IU})$ was added to each tube. Time course incubation of enzyme treated samples was done in a shaking water bath at $37^{\circ} \mathrm{C}$ for $3 \mathrm{~h}$ and aliquot of $1 \mathrm{~mL}$ in triplicates were collected after intervals of $0,30,60,90,120,150$ - and 180-min. For estimation of rapidly digestible starch (RDS) and slowly digestible starch (SDS) fractions, additional aliquots $(1 \mathrm{~mL})$ collected from the reaction mixture after $20 \mathrm{~min}\left(\mathrm{G}_{20}\right)$ and $120 \mathrm{~min}\left(\mathrm{G}_{120}\right)$ of incubation time were used for glucose quantification respectively. Enzyme reaction was stopped by immediate boiling to $100^{\circ} \mathrm{C}$ for $5 \mathrm{~min}$. Final incubation was carried out at $60{ }^{\circ} \mathrm{C}$ for $45 \mathrm{~min}$ by adding $1 \mathrm{~mL}$ of $0.4 \mathrm{M}$ sodium acetate buffer $(\mathrm{pH}=4.75)$ and $80 \mu \mathrm{L}$ of AMG solution $(3300 \mathrm{U} / \mathrm{mL})$ to each aliquot. Aliquot of $100 \mu \mathrm{L}$ was used for glucose measurement after centrifugation of tubes at $2000 \mathrm{~g}$ for $10 \mathrm{~min}$. Glucose released after every $30 \mathrm{~min}$ was quantified using glucose oxidase peroxidase kit (Megazyme, Ireland). The starch digestion rate was expressed as the percentage of total starch (TS) hydrolyzed after $30 \mathrm{~min}$ interval from 0 to $180 \mathrm{~min}$. pGI and hydrolysis index (HI) were calculated using the kinetics of starch digestion. pGI was calculated from the standard formula,

$$
\mathrm{pGI}=39.71+(0.549 \times \mathrm{HI}) .
$$

Total starch content was measured using the total starch assay kit (K-TSTA, Megazyme, Bray, Ireland) by standard $\mathrm{AACC}^{21} .100 \mathrm{mg}$ of powdered sample was mixed with $0.2 \mathrm{~mL}$ of $80 \%$ ethanol followed by addition of $2 \mathrm{~mL}$ cold $\mathrm{NaOH}$ solution $(1.7 \mathrm{M})$. The tubes were placed over a magnetic stirrer in an ice-water bath for $15 \mathrm{~min}$. The contents were stirred in between vigorously to avoid any lump formation. $8 \mathrm{~mL}$ of sodium acetate buffer $(600 \mathrm{mM}, \mathrm{pH}=6.8)$ was added and mixing was done using a vortex shaker. $0.1 \mathrm{~mL}$ of each a amylase (3000 U/ $\mathrm{mL})$ and AMG $(3300 \mathrm{U} / \mathrm{mL})$ were added and mixing was done again for $5 \mathrm{~s}$. Tubes were incubated in a water bath for $30 \mathrm{~min}$ at $50{ }^{\circ} \mathrm{C} .2 \mathrm{~mL}$ of solution was centrifuged at $7000 \mathrm{~g}$ for $5 \mathrm{~min} .1 \mathrm{~mL}$ of supernatant was mixed with $4 \mathrm{~mL}$ of sodium acetate buffer $(100 \mathrm{mM}, \mathrm{pH}=5.0)$. After through mixing, $0.1 \mathrm{~mL}$ of aliquots were treated with $3 \mathrm{~mL}$ of GOPOD reagent and incubated for $20 \mathrm{~min}$ at $50^{\circ} \mathrm{C}$. Absorbance was measured at $510 \mathrm{~nm}$ and total starch was calculated as $\mathrm{g} / 100 \mathrm{~g}$ of sample weight.

Glycemic load of the samples was calculated using the following equation 


\begin{tabular}{|l|l|l|l|}
\hline Variety/genotype & Ecotype & Pedigree & Grain type \\
\hline Lalat & Indica & OBS $677 \times$ IR $2071 \times$ Vikram $\times$ W1263 & Long slender \\
\hline Shalimar Rice-2 & Indica & VL Dhan $221 \times$ K 39 & Long bold \\
\hline Basmati-1509 & Indica & Pusa $1121 \times$ Pusa 1301 & Long slender \\
\hline China-1007 & Indica & Introduction & Medium slender \\
\hline Chenab & Indica & K-21/IR-2053 & Medium slender \\
\hline Jhelum & Indica & JAKKOKU $\times$ IET-1444 & Long bold \\
\hline Koshikari & Japonica & Norin-22 $\times$ Norin-1 & Short bold \\
\hline SKUA-402 & Japonica & Kohsar $\times$ PS 86014-TR 891-7-2-1 & Short bold \\
\hline K-332 & Japonica & Shenei $\times$ Norin-11 & Short bold \\
\hline
\end{tabular}

Table 1. Salient features of rice (Oryza sativa) germplasm lines/varieties.

\begin{tabular}{|c|c|c|c|c|c|c|c|c|c|}
\hline Parameters & Lalat & $S R-2$ & Basmati-1509 & China-1007 & Chenab & Jhelum & Koshikari & SKUA-402 & K-332 \\
\hline Apparent amylose content (\%) & $28.31^{\mathrm{a}} \pm 0.50$ & $22.24^{\mathrm{d}} \pm 1.6$ & $23.52^{\mathrm{b}} \pm 0.6$ & $21.46^{\mathrm{e}} \pm 0.35$ & $22.62^{\mathrm{c}} \pm 0.20$ & $21.0^{f} \pm 0.46$ & $15.40^{\mathrm{i}} \pm 0.48$ & $18.22^{\mathrm{g}} \pm 0.60$ & $16.30^{\mathrm{h}} \pm 0.52$ \\
\hline Amylose class & High & Intermediate & Intermediate & Intermediate & Intermediate & Intermediate & Low & Low & Low \\
\hline Dietary fiber (\%) & $3.97^{\mathrm{a}} \pm 0.02$ & $2.63^{\mathrm{f}} \pm 0.03$ & $3.15^{\mathrm{c}} \pm 0.03$ & $2.40^{\mathrm{g}} \pm 0.05$ & $2.78^{\mathrm{e}} \pm 0.02$ & $2.65^{\mathrm{f}} \pm 0.02$ & $3.45^{\mathrm{b}} \pm 0.04$ & $2.90^{\mathrm{d}} \pm 0.04$ & $2.96^{\mathrm{d}} \pm 0.03$ \\
\hline \multicolumn{10}{|l|}{ Texture profile analysis } \\
\hline Hardness $(\mathrm{N})$ & $4.521^{\mathrm{a}} \pm 0.04$ & $3.382^{\mathrm{e}} \pm 0.03$ & $3.811^{\mathrm{b}} \pm 0.06$ & $3.295^{\mathrm{f}} \pm 0.012$ & $3.491^{\mathrm{d}} \pm 0.04$ & $3.262^{\mathrm{g}} \pm 0.015$ & $3.626^{c} \pm 0.03$ & $1.979^{\mathrm{h}} \pm 0.023$ & $1.234^{\mathrm{i}} \pm 0.016$ \\
\hline Cohesiveness & $0.794^{\mathrm{a}} \pm 0.15$ & $0.615^{\mathrm{e}} \pm 0.15$ & $0.762^{\mathrm{b}} \pm 0.24$ & $0.581^{\mathrm{f}} \pm 0.07$ & $0.623^{\mathrm{d}} \pm 0.03$ & $0.557^{\mathrm{g}} \pm 0.37$ & $0.683^{c} \pm 0.04$ & $0.386^{\mathrm{h}} \pm 0.15$ & $0.312^{\mathrm{i}} \pm 0.02$ \\
\hline Stickiness (N) & $3.218^{\mathrm{h}} \pm 0.06$ & $3.838^{\mathrm{e}} \pm 0.05$ & $3.640^{\mathrm{g}} \pm 0.04$ & $3.940^{\mathrm{d}} \pm 0.17$ & $3.748^{\mathrm{f}} \pm 0.03$ & $3.925^{\mathrm{d}} \pm 0.02$ & $5.858^{c} \pm 0.60$ & $6.083^{b} \pm 0.033$ & $6.710^{\mathrm{a}} \pm 0.55$ \\
\hline
\end{tabular}

Table 2. Apparent amylose content, dietary fiber and textural parameters of different rice genotypes. Results are expressed as mean $\pm S D$ of three replications. Mean values in the rows with different superscripts are significantly different at $\mathrm{p} \leq 0.05$.

$$
G L=\frac{p G I \times \text { available carbohydrate per serving size }}{100} .
$$

Standard $\mathrm{AOAC}^{23}$ procedures were followed for determination of protein, fat, moisture, ash and crude fiber contents. Total carbohydrate content was determined by subtracting the mean values of protein, fat, moisture, ash and crude fiber content from $100^{24}$. Dietary fiber was determined using Dietary Fiber system (FIBRA PLUS $\mathrm{DF}$, Pelican equipments, Chennai) by following approved $\mathrm{AOAC}^{23}$ procedure. Available carbohydrate content per serving size of $100 \mathrm{~g}$ was then calculated as difference of total carbohydrate and dietary fiber ${ }^{17}$.

Texture profile analysis. Texture profile analysis of cooked rice was carried out by texture analyzer (Stable Micro System, TA-XT2i, Surrey, UK) following the procedure reported by Hussain et al. ${ }^{25}$. Textural parameters like hardness, cohesiveness and stickiness were calculated from the inbuilt Texture Expert software.

Statistical analysis. One-way analysis of variance (ANOVA) followed by Duncan's multiple range test was used to determine the statistical difference of measured parameters within the selected rice varieties. Standard statistical software, SPSS was used for data analysis. Pearson's correlation coefficient was computed to determine the relationships among the analyzed parameters.

\section{Results and discussion}

Chemical composition. The proximate composition of selected varieties studied previously by authors is given in Table $S 1^{16,17}$.

Apparent amylose content and allelic variation at $(\mathrm{CT})_{n}$ locus. Apparent amylose content (AAC) of different rice genotypes varied significantly between $15.40 \%$ (Koshikari- a short bold variety) to $28.31 \%$ (Lalata long grain variety) (Tables 1 and 2). As per the classification given by Juliano ${ }^{26}$, the Indica varieties namelyShalimar Rice-2, Basmati-1509, China-1007, Chenab, and Jhelum were classified as intermediate amylose type, Lalat as high amylose variety, whereas Japonica varieties-SKUA-402, Koshikari and K-332 were classified as low amylose type. Feng et al. ${ }^{27}$ also reported lower AAC in Japonica varieties as compared to Indica ones. Amylose content is governed by $W x$ locus that manifests its effect through regulation of starch synthase enzyme GBSS. A gene linked SSR marker RM190 carries dinucleotide $(\mathrm{CT})_{\mathrm{n}}$ repeats in the $5^{\prime}$ Untranslated Region (UTR) of Waxy exon 1 of $W x$ gene $^{11}$ and explains the difference between glutinous and non-glutinous rice ${ }^{28}$. Low amylose Japonica rice varieties- SKUA-402 and K-332 amplified (CT) ${ }_{19}$ allele, whereas, Koshikari amplified (CT) $)_{17}$ allele (Fig. 1). Bao et al. ${ }^{29}$ also found the $\mathrm{CT}_{17}$ to be the most common waxy microsatellite in glutinous rice accessions. Biselli et al. ${ }^{28}$ also reported that alleles $(\mathrm{CT})_{17}$ to $(\mathrm{CT})_{19}$ represent AAC range of $14.92-23.7 \%$. Among the dif- 


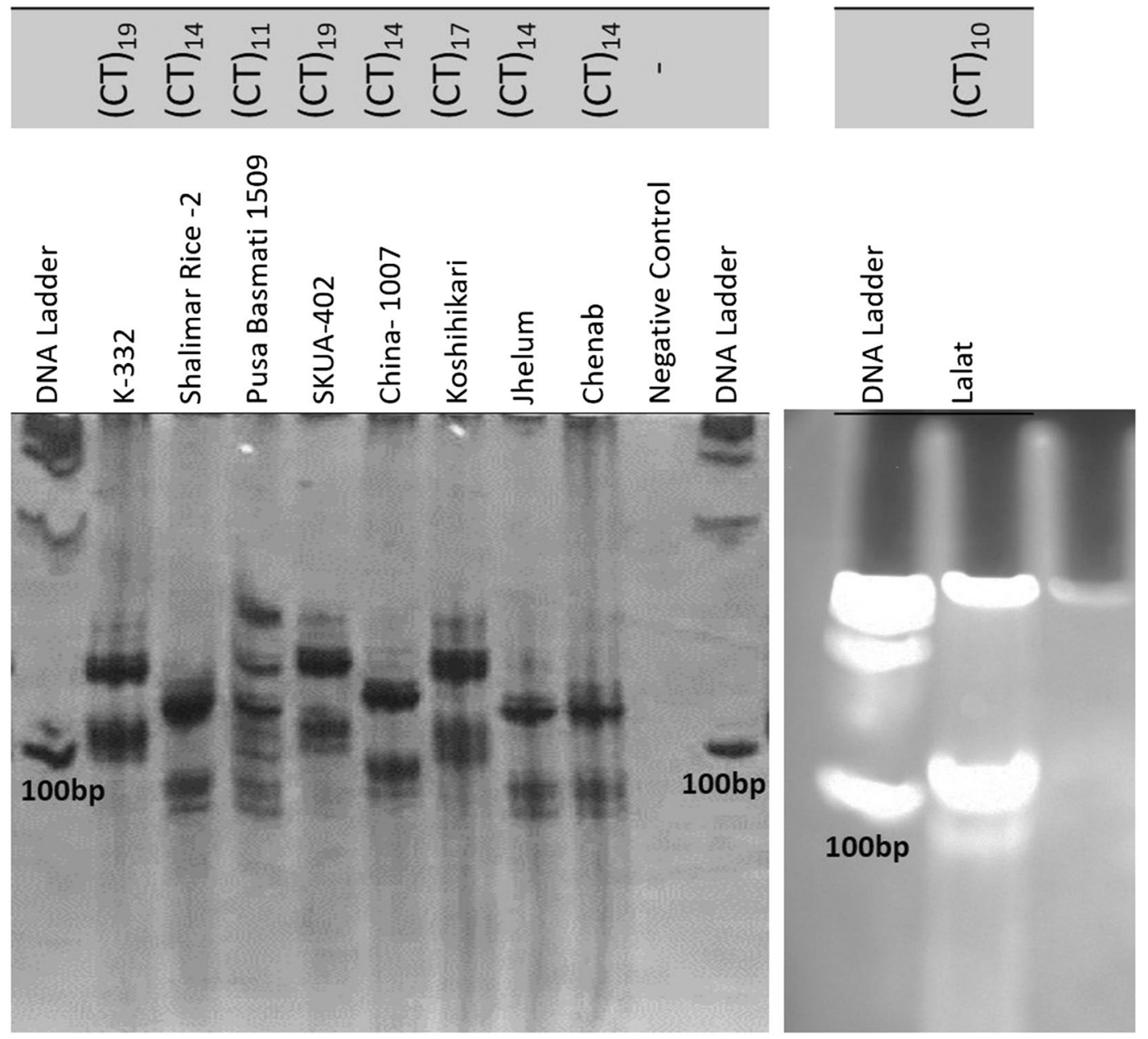

Figure 1. Allelic variation within Waxy gene among rice genotypes at RM190 locus.

ferent Indica varieties, Lalat, carried a CT repeat of 10 that is associated with high amylose and Basmati-1509 amplified (CT) ${ }_{11}$ allele (Fig. 1) which is also associated with high amylose content. However, Shalimar Rice-2, Jhelum, Chenab and China-1107 carried (CT) ${ }_{14}$ allele (Fig. 1) which are associated with low to intermediate amylose content ${ }^{30}$. Cheng et al. ${ }^{31}$ elucidated five $W x$ gene alleles- $\mathrm{CT}_{10}, \mathrm{CT}_{11}, \mathrm{CT}_{16}, \mathrm{CT}_{17}$, and $\mathrm{CT}_{18}$ among the 15 rice varieties and found that high amylose varieties were associated with shorter repeat alleles, namely $\mathrm{CT}_{10}$ and $\mathrm{CT}_{11}$ against the low and intermediate amylose varieties carrying longer repeat alleles $-\mathrm{CT}_{16}, \mathrm{CT}_{17}$ and $\mathrm{CT}_{18}$. Correlation matrix given in Table 3 also showed highly significant $(\mathrm{p}<0.01)$ negative correlation of AAC with $\mathrm{CT}$ repeat $(\mathrm{r}=-0.909)$. Amylose is resistant to enzymatic degradation therefore; high amylose rice varieties usually elicit low GI responses ${ }^{11}$. Overall RM190 is an efficient marker that has been reported to explain $86.4 \%$ of variation in $\mathrm{AAC}^{29}$. The marker explained the inherent variation of AAC within the rice genotypes selected in the present study as well.

In-vitro starch digestibility and dietary fiber. Rapidly digestible starch (RDS), slowly digestible starch (SDS), and resistant starch (RS), affect the rate of starch hydrolyzation and glucose release. RDS contribute to quick glycemic response and SDS contribute to extended glycemic response, while as RS restrains the glucose release and thus minimizes the glycemic respons $\mathrm{e}^{32}$. RDS, SDS, and RS contents showed significant variation among the tested rice varieties (Table 4). RS content of different varieties varied from 0.43 (K-332) to $2.85 \%$ (Lalat), SDS from 14.93 (Jhelum) to 34.72\% (Lalat) (Table 4) and RDS from 62.43 (Lalat) to 84.61\% (Jhelum). Out of all the selected varieties, Lalat showed lowest RDS and maximum RS and SDS followed by Basmati-1509 and Koshikari. Table 3 indicated that AAC exhibited significant positive correlation $(\mathrm{r}=0.719, \mathrm{p}<0.05)$ with RS. Many studies in past have also reported positive correlations of RS and amylose content $\mathrm{t}^{33-35}$. It is well documented that RS content increases in cooked rice during cooling due to retrogradation ${ }^{36}$. The polymeric structures of amylose molecules form double helix crystals which are more resistant to zymolysis ${ }^{37}$. The intermediate to high amylose rice varieties usually have higher RS content after cooking as compared to low amylose varieties $^{15}$. In present study also, RS content was recorded maximum (2.85\%) in high amylose rice variety (Lalat) followed by Basmati-1509 (1.85\%) - an intermediate amylose variety, while as low amylose varieties, SKUA402 and $K-332$ had relatively lower RS contents of 0.54 and $0.43 \%$, respectively (Table 4 ). Similar trends were 


\begin{tabular}{|c|c|c|c|c|c|c|c|c|c|c|c|c|c|}
\hline & AAC & $(\mathrm{CT}) \mathrm{n}$ & RDS & SDS & RS & DF & Fat & Protein & pGI & GL & H & $\mathrm{COH}$ & Stickiness \\
\hline AAC & 1 & & & & & & & & & & & & \\
\hline$(\mathrm{CT}) \mathrm{n}$ & $-0.909^{* *}$ & 1 & & & & & & & & & & & \\
\hline RDS & -0.525 & 0.530 & 1 & & & & & & & & & & \\
\hline SDS & 0.444 & -0.446 & $-0.899^{* *}$ & 1 & & & & & & & & & \\
\hline RS & $0.719^{*}$ & $-0.755^{\star}$ & $-0.937^{* *}$ & $0.847^{* *}$ & 1 & & & & & & & & \\
\hline $\mathrm{DF}$ & 0.284 & -0.297 & $-0.928^{* *}$ & $0.880^{* *}$ & $0.797^{\star}$ & 1 & & & & & & & \\
\hline Fat & 0.235 & -0.218 & $-0.831^{* *}$ & $0.673^{*}$ & $0.707^{\star}$ & $0.771^{*}$ & 1 & & & & & & \\
\hline Protein & -0.151 & -0.084 & -0.480 & 0.291 & 0.376 & 0.629 & 0.528 & 1 & & & & & \\
\hline pGI & $-0.728^{\star}$ & $0.827^{\star *}$ & $0.853^{\star *}$ & $-0.801^{* *}$ & $-0.949^{* *}$ & $-0.723^{\star}$ & $-0.783^{\star}$ & $-0.690^{*}$ & 1 & & & & \\
\hline GL & -0.646 & $0.761^{\star}$ & $0.885^{* *}$ & $-0.855^{\star \star}$ & $-0.944^{* *}$ & $-0.791^{*}$ & $-0.796^{*}$ & $-0.686^{*}$ & $0.986^{* *}$ & 1 & & & \\
\hline $\mathrm{H}$ & $0.729^{*}$ & $-0.881^{* *}$ & -0.552 & 0.425 & $0.745^{\star}$ & 0.410 & 0.279 & 0.387 & $-0.875^{* *}$ & $-0.818^{* *}$ & 1 & & \\
\hline $\mathrm{COH}$ & $0.726^{\star}$ & $-0.910^{* *}$ & -0.607 & 0.536 & $0.766^{\star}$ & 0.420 & 0.360 & 0.315 & $-0.900^{* *}$ & $-0.870^{* \star}$ & $0.924^{\star *}$ & 1 & \\
\hline Stickiness & $-0.893^{* *}$ & $0.935^{\star *}$ & 0.250 & -0.166 & -0.525 & -0.014 & 0.029 & 0.099 & 0.639 & 0.540 & $-0.832^{* *}$ & $-0.799^{* *}$ & 1 \\
\hline
\end{tabular}

Table 3. Correlation matrix between various chemical and textural parameters. $A A C$ apparent amylose content, $(C T) n$ cytosine and thymine repeats, $R D S$ rapidly digestible starch, $S D S$ slowly digestible starch, $R S$ resistant starch, $D F$ dietary fiber, $p G I$ predicted glycemic index, GL glycemic load, $H$ hardness, $C O H$ cohesiveness. ${ }^{*}$ Correlation is significant at the level $0.01 .{ }^{*}$ Correlation is significant at the level 0.05 .

\begin{tabular}{|l|l|l|l|l|}
\hline Variety & RDS \% & SDS \% & RS \% & TS \% \\
\hline SR-2 & $80.15^{\mathrm{d}} \pm 0.5$ & $19.08^{\mathrm{e}} \pm 0.2$ & $0.77^{\mathrm{c}} \pm 0.2$ & $74.42^{\mathrm{c}} \pm 1.1$ \\
\hline Basmati-1509 & $73.45^{\mathrm{b}} \pm 0.7$ & $24.70^{\mathrm{g}} \pm 1.2$ & $1.85^{\mathrm{g}} \pm 0.9$ & $75.10^{\mathrm{d}} \pm 0.9$ \\
\hline China-1007 & $83.17^{\mathrm{f}} \pm 0.4$ & $15.88^{\mathrm{b}} \pm 0.9$ & $0.95^{\mathrm{e}} \pm 0.7$ & $76.15^{\mathrm{f}} \pm 1.2$ \\
\hline Chenab & $83.05^{\mathrm{f}} \pm 0.3$ & $16.15^{\mathrm{c}} \pm 0.6$ & $0.80^{\mathrm{d}} \pm 0.6$ & $80.39^{\mathrm{g}} \pm 0.8$ \\
\hline Jhelum & $84.61^{\mathrm{g}} \pm 1.1$ & $14.93^{\mathrm{a}} \pm 0.2$ & $0.46^{\mathrm{a}} \pm 0.3$ & $75.65^{\mathrm{e}} \pm 1.3$ \\
\hline Koshikari & $75.25^{\mathrm{c}} \pm 0.3$ & $23.58^{\mathrm{f}} \pm 0.1$ & $1.17^{\mathrm{f}} \pm 0.5$ & $73.54^{\mathrm{b}} \pm 1.2$ \\
\hline SKUA-402 & $81.14^{\mathrm{e}} \pm 1.4$ & $18.32^{\mathrm{d}} \pm 0.3$ & $0.54^{\mathrm{b}} \pm 0.3$ & $75.77^{\mathrm{e}} \pm 1.5$ \\
\hline K-332 & $80.10^{\mathrm{d}} \pm 0.5$ & $19.47^{\mathrm{e}} \pm 0.5$ & $0.43^{\mathrm{a}} \pm 0.2$ & $76.69^{\mathrm{f}} \pm 0.7$ \\
\hline Lalat & $62.43^{\mathrm{a}} \pm 0.2$ & $34.72^{\mathrm{h}} \pm 0.6$ & $2.85^{\mathrm{h}} \pm 1.2$ & $68.13^{\mathrm{a}} \pm 0.8$ \\
\hline
\end{tabular}

Table 4. Variation in rapidly digestible starch (RDS), slowly digestible starch (SDS), resistant starch (RS) and total starch (TS) of different rice varieties. Mean values within the columns with different superscripts differ significantly at $\mathrm{p}<0.05$.

reported by Park et al. ${ }^{37}$ for Korean rice cultivars with different amylose contents and Chen et al ${ }^{30}$ for low, intermediate and high amylose rice varieties of United States. However, Koshikari despite being a low amylose variety also showed higher RS content (1.17\%) (Table 4), which can be attributed to its relatively higher fat $(0.86 \%)$ (Table S1) and dietary fiber (DF) content (3.45\%) (Table 2). Table 3 also indicated significant positive correlations of RS with fat $(\mathrm{r}=0.707, \mathrm{p}<0.05)$. Besides RS, fat content also showed significant positive correlation with SDS $(r=0.673, p<0.05)$ and negative correlation with RDS $(r=-0.831, p<0.01)$ Since, interaction of amylose content and lipid fraction is responsible for formation of type- 5 RS. Thus, the inference drawn was that it is not only the amylose content but its interaction with lipids which attenuates the glycemic response. The correlation studies given in Table 3 also indicated that RS is more significantly correlated with pGI $(r=-0.949, p<0.01)$ as compared to AAC. Both RS and DF act in a complementary way in lowering the glycemic response ${ }^{15,38}$. Within the digestive tract, both RS and DF are more resistant to digestion and thus, help in lowering the blood glucose levels. In the present study, DF showed significant positive correlations with $R S(r=0.797, p<0.05)$, and SDS $(r=0.880, p<0.01)$ whereas, RDS showed significant negative correlation with DF $(r=0.928, p<0.01)$ (Table 3).

Predicted glycemic index and glycemic load. Kinetics of starch digestion analyzed for 0-180 min given in Fig. 2a revealed a rapid increase in the digestibility of starch during first $30 \mathrm{~min}$ of incubation followed by a steady digestion rate with the progression of time. The predicted GI values of different rice varieties ranged from 50.12 (Lalat) to 84.22 (K-332) (Fig. 2b). As per WHO ${ }^{39}$ classification, SR-2, China-1007, Chenab, Jhelum, SKUA-402 and K-332 were classified as high GI varieties (GI $\geq 70)$; Basmati-1509 and Koshikari as medium GI varieties $(\mathrm{GI}=56-69)$ and Lalat as low GI variety $(\mathrm{GI} \leq 55)$, All the medium slender, long bold and short bold varieties elicited high GI scores which is in accordance with the results reported by Prasad et al. ${ }^{15}$ for popular Indian rice varieties. Although being a short bold variety, Koshikari showed intermediate pGI score of 63.11, which can be attributed to its higher RS, DF, fat and protein contents as compared to other short bold varieties (Table S1 and Table 2). Amylose fraction of starch in combination with lipid fraction forms type-5 resistant $\operatorname{starch}^{40}$. In addition, interaction between starch, lipids and proteins result in the formation of highly 


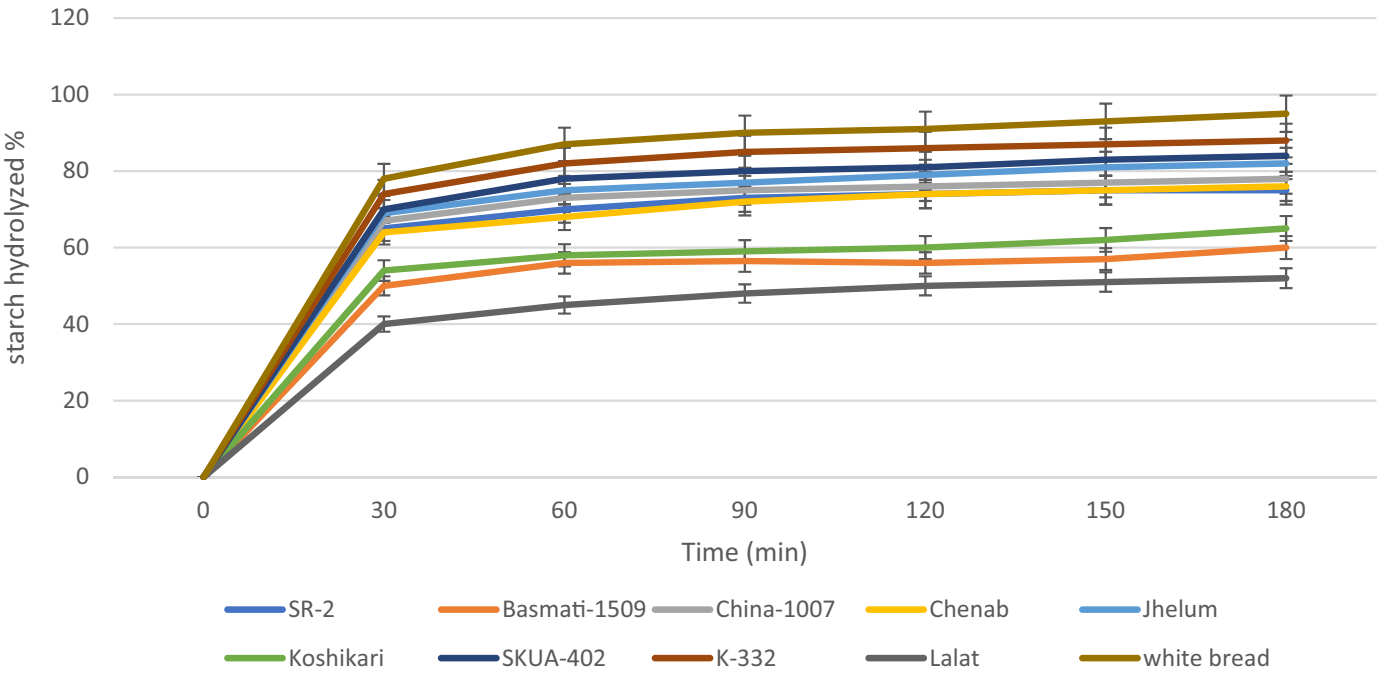

a)

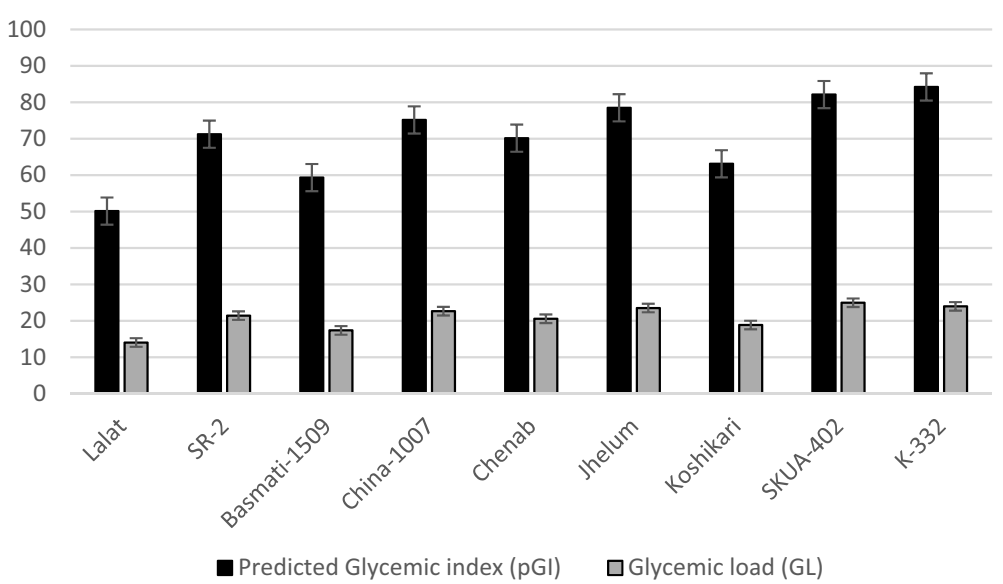

b)

Figure 2. (a) Kinetics of starch hydrolysis of rice varieties from 0 to $180 \mathrm{~min}$. (b) Predicted glycemic index and glycemic load of different rice varieties.

ordered ternary complexes with greater resistance to amylolysis ${ }^{41}$. Such type of complexations imparts steric hinderance to the carbolytic enzyme action and are responsible for lowering of glycemic index due to their reduced digestibility ${ }^{40}$. pGI exhibited significant negative correlations with fat $(\mathrm{r}=-0.763, \mathrm{p}<0.05)$ and protein $(\mathrm{r}=-0.690, \mathrm{p}<0.05)$. The two long slender type varieties (Basmati-1509 and Lalat) selected in the present study exhibited intermediate and low GI score respectively. Ranawana et al. ${ }^{42}$ also reported lower glycemic scores for long-grain rice varieties. pGI showed inverse relationship with AAC $(\mathrm{r}=-0.728, \mathrm{p}<0.05)$ and a direct relationship with $(\mathrm{CT})$ repeats $(\mathrm{r}=+0.827, \mathrm{p}<0.01)$ (Table 3). Therefore, the low GI score (50.12) of Lalat can be attributed to its high AAC (28.31\%) and least CT value (10) as compared to other varieties (Table 2 and Fig. 1). Fitzgerald et al. ${ }^{12}$ also reported strong negative correlation between amylose content, and GI in different rice varieties of Asian region. Besides AAC, RS and DF also showed negative correlations with pGI $(r=-0.949$, $\mathrm{p}<0.01 ; \mathrm{r}=-0.723, \mathrm{p}<0.05$, respectively) (Table 3). Lalat, Basmati-1509 and Koshikari having higher RS and DF contents showed lower glucose release after $120 \mathrm{~min}$ of hydrolysis which explains their GI lowering effect relative to other varieties (Fig. 2a,b). Further, the longer amylopectin chains usually present in high and intermediate amylose rice tends to form more rigid double helixes which are susceptible to retrogradation and resistant to enzymatic hydrolysis ${ }^{43}$. Thus, various factors other than amylose contribute to GI variation within the same amylose class in rice. Fitzgerald et al. ${ }^{12}$ also reported GI range of $48-92$ in a diverse set of rice varieties. Chandel et al. ${ }^{38}$ analyzed the in-vitro GI of five rice cultivars of Chhattisgarh region and reported GI in the range of 55-68 for tested rice genotypes.

The glycemic response of food upon ingestion depends not only on the GI but also on the total amount of carbohydrates consumed. Thus, in order to estimate the glycemic response of a specific portion of food, glycemic load (GL) was also estimated. GL score of $<10$ is considered as low; 11-19 as intermediate and $>20$ as high $^{44}$. For the selected set of rice varieties, GL showed significant variation between 14.04 (Lalat) to 24.95 
(SKUA-402) (Fig. 2b). Out of all the selected varieties, Lalat (14.04), Koshikari (18.84) and Basmati-1509 (17.36) were identified as intermediate GL varieties, while as SR-2 (21.43), China-1007 (22.64), Chenab (20.56), Jhelum (23.50), SKUA-402 (24.95) and K-332 (23.95) as high GL varieties. GL showed highly significant positive correlation $(\mathrm{r}=+0.986, \mathrm{p}<0.01)$ with $\mathrm{pGI}$ and negative correlations with $\mathrm{RS}(\mathrm{r}=-0.944, \mathrm{p}<0.01)$, DF $(\mathrm{r}=-0.791$, $\mathrm{p}<0.05)$, protein $(\mathrm{r}=-0.676, \mathrm{p}<0.05)$ and fat $(\mathrm{r}=-0.736, \mathrm{p}<0.05)$ (Table 3). Lalat despite having low GI showed intermediate GL, possibly due to higher portion size selected for estimation of GL. Keeping in view, the rice consumption pattern of Northern Himalayan regions, the portion size of $100 \mathrm{~g}$ was chosen in the present study.

Texture profile analysis. Textural properties of selected rice varieties determined after cooking are illustrated in Table 2. Hardness $(\mathrm{H})$ and cohesiveness $(\mathrm{COH})$ exhibited significant positive correlations with AAC $(\mathrm{r}=0.729, \mathrm{p}<0.05 ; \mathrm{r}=0.726, \mathrm{p}<0.05$, respectively) while stickiness showed significant negative correlation $(\mathrm{r}=-0.893, \mathrm{p}<0.01)$ with AAC (Table 3). Stickiness of rice is governed by leaching of amylopectin over amylose, because the size of leached amylopectin molecules is many times smaller than leached amylose molecules ${ }^{45}$. During cooking, the amylopectin molecules leach out more in low amylose varieties, which increases their sticky behaviour and reduces their hardness and cohesiveness as compared to intermediate and high amylose rice varieties ${ }^{45}$. Amongst the selected Indica and Japonica varieties, the trends recorded for $\mathrm{H}$ and COH were Lalat $>$ Basmati-1509 $>$ Chenab $>$ SR-2 $>$ China-1007 $>$ Jhelum and Koshikari $>$ SKUA-402 $>$ K-332, respectively, while for stickiness, the trends recorded for Indica and Japonica varieties were Jhelum $>$ China1007 $>$ SR-2 $>$ Chenab $>$ Basmati-1509 $>$ Lalat and K-332 $>$ SKUA-402 > Koshikari, respectively (Table 2). Perusal of the results given in Table 2 indicated that both $\mathrm{H}$ and $\mathrm{COH}$ were higher, while stickiness was lower in Indica varieties than Japonica ones, which is in concomitance with the previous findings reported by Lu et al. ${ }^{46}$ and $\mathrm{Li}$ et $\mathrm{al}^{47}$. Within the Indica and Japonica classes, both $\mathrm{H}$ and $\mathrm{COH}$ were higher while stickiness was lower in varieties having higher AAC (Table 2). However, Koshikari despite being a low amylose Japonica variety showed significantly higher hardness and cohesiveness as compared to other Japonica varieties and some intermediate Indica varieties which might be due to its higher RS and protein contents (Table 2 and Table S1). Lu et al. ${ }^{46}$ also reported that amount and chemical nature of solids affect the textural profile parameters of cooked rice. Apart from AAC, $\mathrm{H}$ and $\mathrm{COH}$ showed significant positive correlations with $\mathrm{RS}(\mathrm{r}=0.745, \mathrm{p}<0.05 ; \mathrm{r}=0.766$, $\mathrm{p}<0.05$, respectively) (Table 3 ). Out of all the selected set of varieties, maximum hardness $(4.515 \mathrm{~N})$ and cohesiveness (0.798) were recorded in Lalat followed by Basmati-1509 $(\mathrm{H}=3.812 \mathrm{~N}$ and $\mathrm{COH}=0.760)$ and Koshikari $(\mathrm{H}=3.524 \mathrm{~N}$ and $\mathrm{COH}=0.680)$ (Table 2). It was thus, presumed that amylose content, resistant starch and other grain components have a strong influence on textural properties of cooked rice.

\section{Conclusion}

In the present study, the in-vitro starch digestibility and kinetics of starch digestion were studied in different rice varieties commonly cultivated and consumed in Northern Highland Himalayan regions and it was confirmed that substantial differences exist in their starch digestibility and glycemic response. Within same amylose class, significant disparity existed in glycemic index and glycemic load. It might be assumed that besides amylose content, resistant starch and other grain components like dietary fiber, protein and fat also effect the glycemic response. Although the variability within $W x$ allele at RM190 locus showed high association with the amylose content. However, the possibility that other genes may also affect the GI, cannot be precluded. Therefore, future studies are needed to identify such genes and to evaluate their effects on GI. In the present study, it was also observed that varieties having lower pGI and relatively higher RS content were harder and less sticky upon cooking. Therefore, besides enhancing the RS content and lowering the pGI, there is need to emphasis on development of soft textured high amylose rice in future rice breeding programmes related to management of diabetes. In addition to low GI rice variety-Lalat; Basmati-1509 and Koshikari due to their medium pGI and relatively high resistant starch, dietary fiber and protein content can also emerge as novel varieties in future, which can be explored in long term public health strategies for management of diabetes in Northern Highland Himalayan regions, where rice is a stable food.

Received: 3 March 2021; Accepted: 17 May 2021

Published online: 08 June 2021

\section{References}

1. Chan, J. C. et al. Diabetes in Asia: Epidemiology, risk factors, and pathophysiology. JAMA 301(20), 2129-2140 (2009).

2. Nanditha, A. et al. Diabetes in Asia and the Pacific: Implications for the global epidemic. Diabetes Care 39(3), 472-485 (2016).

3. International Diabetes Federation. IDF Diabetes Atlas, Ninth edition. ISBN: 978-2-930229-87-4 https://www.diabetesatlas.org/ en/ (2019).

4. Shahbandeh. Total global rice consumption. https://www.statista.com/statistics/255977/total-global-rice-consumption/ (2021).

5. Chakraborty, M. A. \& Murray, E. V. Rice production and productivity in Andhra Pradesh. Tech. Rep. https://doi.org/10.13140/ RG.2.1.2919.1203 (2011).

6. Villegas, R. et al. Prospective study of dietary carbohydrates, glycemic index, glycemic load, and incidence of type 2 diabetes mellitus in middle-aged Chinese women. Arch. Intern. Med. 167(21), 2310-2316 (2007).

7. Hu, E. A., Pan, A., Malik, V. \& Qi, S. White rice consumption and risk of type 2 diabetes: Meta-analysis and systematic review. BMJ 344, 1454 (2012).

8. Golozar, A. et al. White rice intake and incidence of type-2 diabetes: Analysis of two prospective cohort studies from Iran. BMC Public Health 17(1), 1-11 (2017).

9. Frei, M., Siddhuraju, P. \& Becker, K. Studies on the in vitro starch digestibility and the glycemic index of six different indigenous rice cultivars from the Philippines. Food Chem. 83(3), 395-402 (2003). 
10. Wan, Y. X. et al. Genetic polymorphism of Wx gene and its correlation with main grain quality characteristics in rice. Rice Sci. 14(2), 85-93 (2007).

11. Bligh, H. F. J. A microsatellite sequence closely linked to the waxy gene of O. sativa. Euphytica 86, 83-85 (1995).

12. Fitzgerald, M. A. et al. Identification of a major genetic determinant of glycaemic index in rice. Rice 4(2), 66-74 (2011).

13. Fuentes-Zaragoza, E. et al. Resistant starch as prebiotic: A review. Starch-Starke 63, 406-415 (2011).

14. Farooq, A. M., Dhital, S., Li, C., Zhang, B. \& Huang, Q. Effects of palm oil on structural and in vitro digestion properties of cooked rice starches. Int. J. Biol. Macromol. 107, 1080-1085 (2018).

15. Prasad, V. S. S., Hymavathi, A., Babu, V. R. \& Longvah, T. Nutritional composition in relation to glycemic potential of popular Indian rice varieties. Food Chem. 238, 29-34 (2019).

16. Naseer, B., Naik, H. R., Hussain, S. Z., Qadri, T., \& Beigh, M. A. Visco-thermal behaviour and structural characterization of temperate highland Himalayan rice cultivars. Starch-Stärke. 3-4, 1-13 (2020).

17. Naseer, B., Naik, H. R., Hussain, S. Z., Zargar, I., Bhat, T. A., \& Nazir, N. Effect of carboxymethyl cellulose and baking conditions on in-vitro starch digestibility and physico-textural characteristics of low Glycemic Index gluten-free rice cookies. LWT. 141, 1-12 (2021).

18. Murray, M. G. \& Thompson, M. F. Rapid isolation of high molecular weight plant DNA. Nucleic Acids Res. 8, 4321-4325 (1980).

19. Huang, L. et al. A fast silver staining protocol enabling simple and efficient detection of SSR markers using a non-denaturing polyacrylamide gel. J. Vis. Exp. 134, 57192 (2018).

20. Chen, M. H., Bergman, C. J., McClung, A. M., Everette, J. D. \& Tabien, R. E. Resistant starch: Variation among high amylose rice varieties and its relationship with apparent amylose content, pasting properties and cooking methods. Food Chem. 234, 180-189 (2017).

21. AACC. American association of cereal Chemists: "Approved methods of the AACC". AACC". Methods, 76(11). St.Paul, MN, USA (1976).

22. Goñi, I., García-Alonso, A. \& Saura-Calixto, F. A starch hydrolysis procedure to estimate glycemic index. Nutr. Res. 17(3), 427-437 (1997).

23. AOAC. Official Methods of Analysis 18th edn. (Association of Official Analytical Chemists, 2005).

24. FAO, WHO. Carbohydrates in human nutrition: Report of a joint FAO/WHO expert consultation. FAO Food Nutr. Pap. 66, 1-140 (1998).

25. Hussain, S. Z. et al. Effect of radiofrequency induced accelerated ageing on physico-chemical, cooking, pasting and textural properties of rice. $L W T$. 139, 110595 (2021).

26. Juliano, B. O. Structure and function of the rice grain and its fractions. Cereal Foods World 37, 772-774 (1992).

27. Feng, F., Li, Y., Qin, X., Liao, Y. \& Siddique, K. H. Changes in rice grain quality of Indica and Japonica type varieties released in China from 2000 to 2014. Front. Plant Sci. 8, 1863 (2017).

28. Biselli, C. et al. Improvement of marker-based predictability of Apparent Amylose Content in japonica rice through GBSSI allele mining. Rice 7(1), 1-18 (2014).

29. Bao, J. S., Coke, H. \& Sun, M. Microsatellites in starch-synthesizing genes in relation to starch physicochemical properties in waxy rice (Oryza sativa L.). Theor. Appl. Genet. 105, 898-905 (2002).

30. Chen, M. H., Bergman, C. J., Pinnson, S. R. M. \& Fjellstrom, R. G. Waxy gene haplotypes: Associations with apparent amylose content and the effect by the environment in an international rice germplasm collection. J. Cereal Sci. 47, 536-545 (2008).

31. Cheng, A., Ismail, I., Osman, M. \& Hashim, H. Simple and rapid molecular techniques for identification of amylose levels in rice varieties. Int. J. Mol. Sci. 13(5), 6156-6166 (2012).

32. Krishnan, V. et al. Cooking fat types alter the inherent glycaemic response of niche rice varieties through resistant starch (RS) formation. Int. J. Biol. Macromol. 162, 1668-1681 (2020).

33. Kong, X. et al. Relationships among genetic, structural, and functional properties of rice starch. J. Agric. Food Chem. 63(27), 6241-6248 (2015)

34. Parween, S. et al. Balancing the double-edged sword effect of increased resistant starch content and its impact on rice texture: Its genetics and molecular physiological mechanisms. Plant Biotechnol. J. 18(8), 1763-1777 (2020).

35. Gani, A. et al. Resistant starch from five Himalayan rice cultivars and Horse chestnut: Extraction method optimization and characterization. Sci. Rep. 10(1), 1-9 (2020).

36. Juliano, B. O. Rice in Human Nutrition (International Rice Research Institute, 1993).

37. Park, J., Oh, S. K., Chung, H. J. \& Park, H. J. Structural and physicochemical properties of native starches and non-digestible starch residues from Korean rice cultivars with different amylose contents. Food Hydrocoll. 102, 105544 (2020).

38. Chandel, G. et al. In vitro identification of low glycemic index (GI) white rice using nutriscan GI analyzer. Adv. Life Sci. 5(23), 11090-11098 (2016)

39. WHO. Healthy eating habits for patients with diabetes 2. In, 2. A noncommunicable disease education manual for primary health care professionals and patients. ISBN 978929061807 (2017).

40. Wang, S. et al. Starch-lipid and starch-lipid-protein complexes: A comprehensive review. Compreh. Rev. Food Sci. Food Safety 19(3), 1056-1079 (2020).

41. Wang, S., Wang, S., Liu, L., Wang, S. \& Copeland, L. Structural orders of wheat starch do not determine in vitro enzymatic digestibility. J. Agric. Food Chem. 65, 1697-1706 (2017).

42. Ranawana, D. V., Henry, C. J. K., Lightowler, H. J. \& Wang, D. Glycaemic index of some commercially available rice and rice products in Great Britain. Int. J. Food Sci. Nutr. 60(sup4), 99-110 (2009).

43. Tuaño, A. P. P., Barcellano, E. C. G., \& Rodriguez, M. S. Resistant starch levels and in vitro starch digestibility of selected cooked philippine brown and milled rices varying in apparent amylose content and glycemic index. Food Chem. Mol. Sci. https://doi.org/ 10.1016/j.fochms.2021.100010 (2021).

44. Venn, B. J. \& Green, T. J. Glycemic index and glycemic load: Measurement issues and their effect on diet-disease relationships. Eur. J. Clin. Nutr. 61(1), S122-S131 (2007).

45. Li, H., Fitzgerald, M. A., Prakash, S., Nicholson, T. M. \& Gilbert, R. G. The molecular structural features controlling stickiness in cooked rice, a major palatability determinant. Sci. Rep. 7(1), 1-12 (2017).

46. Lu, S., Cik, T. T., Lii, C. Y., Lai, P. \& Chen, H. H. Effect of amylose content on structure, texture and $\alpha$-amylase reactivity of cooked rice. LWT Food Sci. Technol. 54(1), 224-228 (2013).

47. Li, H., Prakash, S., Nicholson, T. M., Fitzgerald, M. A. \& Gilbert, R. G. Instrumental measurement of cooked rice texture by dynamic rheological testing and its relation to the fine structure of rice starch. Carbohyd. Polym. 146, 253-263 (2016).

\section{Acknowledgements}

Authors duly acknowledge the financial support provided by Council of Scientific and Industrial Research (CSIR, New Delhi), India and All India Coordinated Research Project on Post-Harvest Engineering and Technology, CIPHET Ludhiana. Authors are highly thankful to Dr S. K. Tyagi, Project Coordinator, AICRP on PHET for supporting the present study and Dr. Manuj Kumar Panda, Department of Processing and Food Engineering, Orissa University of Agricultural and Technology, India, for providing the high amylose variety for this study. 


\section{Author contributions}

B.N. did the investigation and wrote the manuscript. H.R.N. supervised the research work. S.Z.H. designed the work. A.B.S. provided the resources for investigation. N.N. was involved in data analysis.

\section{Competing interests}

The authors declare no competing interests.

\section{Additional information}

Supplementary Information The online version contains supplementary material available at https://doi.org/ 10.1038/s41598-021-91537-0.

Correspondence and requests for materials should be addressed to S.Z.H.

Reprints and permissions information is available at www.nature.com/reprints.

Publisher's note Springer Nature remains neutral with regard to jurisdictional claims in published maps and institutional affiliations.

(c) (i) Open Access This article is licensed under a Creative Commons Attribution 4.0 International License, which permits use, sharing, adaptation, distribution and reproduction in any medium or format, as long as you give appropriate credit to the original author(s) and the source, provide a link to the Creative Commons licence, and indicate if changes were made. The images or other third party material in this article are included in the article's Creative Commons licence, unless indicated otherwise in a credit line to the material. If material is not included in the article's Creative Commons licence and your intended use is not permitted by statutory regulation or exceeds the permitted use, you will need to obtain permission directly from the copyright holder. To view a copy of this licence, visit http://creativecommons.org/licenses/by/4.0/.

(C) The Author(s) 2021 